\title{
Comparative Study of the Effect of Cereals (Guinea Corn and Wheat) on The Physico- Mechanical Properties of Tunga and Chanchaga Core Making Sands
}

\author{
B.O. Araoye ${ }^{1}$, B.M. Bosan ${ }^{2}$, U.B.S. Abubakar ${ }^{3},{ }^{4}$ T.S. Ayeni, ${ }^{5}$ E.M. Dogara, ${ }^{6}$ O.H. Adejo, ${ }^{7}$ D.A. Abugi \\ $1,2,3,4,5,6,7$ (National Metallurgical Development Centre, Jos, Nigeria)
}

\begin{abstract}
The study presents the effect of cereals (Guinea corn and wheat) on the properties of clay-bonded foundry core sand from deposits in Niger state. The research analyses the physic-mechanical properties of prepared sand samples obtained from the two locations namely Tunga and Chanchaga core making sand respectively. Results obtained from test conducted on various mixtures studied indicated that the cereals used significantly improved the strengths, both compressive and shear in the green and dry states of the core samples produced. This shows that local additives as foundry core mixtures can effectively be used as substitutes for imported ore.
\end{abstract}

Keywords - Cereals, Core-making, Strength, Silica sand and Casting

\section{INTRODUCTION}

Foundry practice in Nigeria can be traced back as far before the pre-colonial era but the country has not significantly benefitted from these foundries partly due to knowledge gap between the local foundrymen and the professionals.

Foundry industries in Nigeria are faced with numerous challenges, [1] revealed that almost all foundries in Nigeria embark on sand casting technique with $60 \%$ of the raw materials needed imported. The properties of sand for casting is a crucial factor in foundry practice. It is important to have good knowledge of this materials, this will greatly assist in determining there suitability for foundry use. The properties and behaviour of sand when known give a clue on the mould and core moulding sand which must be readily mouldable and produce defect free casting. The properties of sand varies and some sands tend to be defective in properties.

Casting plays important roles in the production of modern equipment for transportation, communication, power, agriculture, agro-allied, construction, space, chemical and petrochemical among others. In casting, there is need for a good binder with high temperature resistance, good collapsibility after casting whilst giving smooth surface finish to the cast. A binder is the second most important component after sand in the mould [2]. Proper selection of a good binder is as important as the moulding sand as it serves to hold the sand grains together; impact strength, resistance to erosion and to breakage, also degree of collapsibility [3-6]. Organic binders have excellent breakdown properties which makes them ideal for cores of casting where accessibility for fettling is difficult and the reduced fettling cost make these binder economical. Inorganic (clay, aqueous, sodium, silicates, bentonite, silicon flour and iron oxide) binders gives additional green strength, retard or increase collapsibility of a core and to prevent cutting or penetration [4-6]. In this study, effort was made in improving the physico-mechanical properties of foundry sand by adding some additives (Guinea corn and Wheat) to better enhance the foundry sand for good casting and also mitigate against high cost of raw materials (e.g. binders) whilst giving optimal casting output.

\subsection{Brief Description of the Study Area}

Chanchaga and Tunga are both community under Chanchaga local government area of Niger state with an area of $72 \mathrm{~km}^{2}$. The distance between Chanchaga and Tunga is about 13 minutes drive by road approximately $4.9 \mathrm{~km}$ apart. 


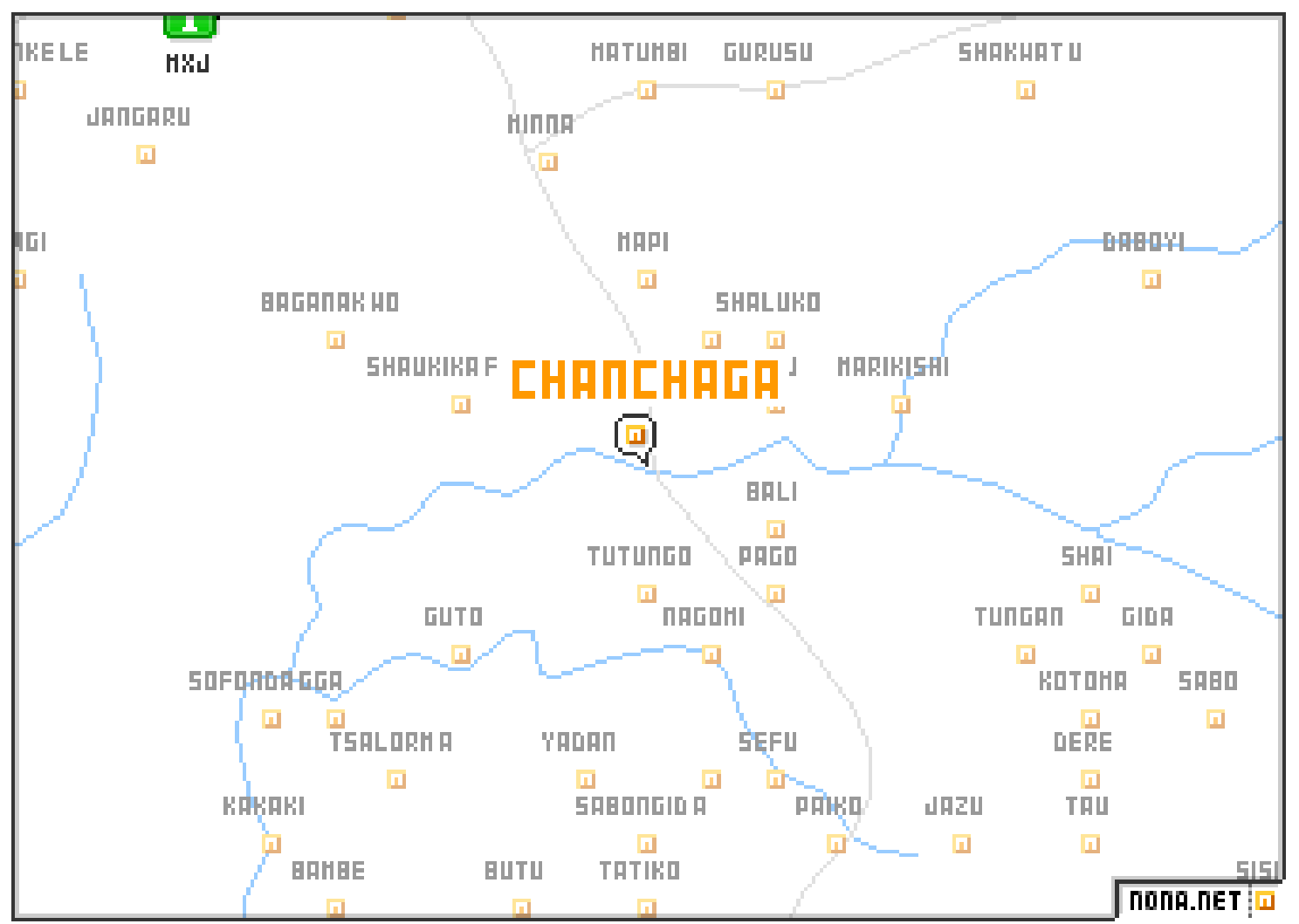

Source: nona.net

\subsection{MATERIALS AND METHODS}

\subsection{Materials}

To conduct the experimental work, the sand sample for these were collected from two major locations in Niger state Nigeria namely:

\section{i. Chanchaga \\ ii. Tunga area}

The cereal (Guinea corn \& Wheat) used as binder were sourced locally from the season farmer in the country. Global Positioning System GPS, array of sieves etc.

\subsection{Methods}

The American Foundry Men Society standard AFS was employ to determine the foundry sand properties of the samples in order to ascertain their suitability for foundry applications. The physical properties of the clay bonded core sand were conducted and the results presented in Bar graph.

\subsection{Experimental Section}

The two deposits namely chanchaga and Tunga were selected to provide information on the suitability for exploitation and use in foundry application in Niger state and Nigeria at large. Five test sand sample namely test 1 - test 5 were prepared from the bulk sample taken from the aforementioned location. The proportionate percent mixture of the wheat and Guinea corn were varied as represented below: 
Table 1: Percentage variation of Wheat and Guinea Corn

\begin{tabular}{|l|c|c|}
\hline Sample & \% Wheat & \% Guinea corn \\
\hline Test 1 & - & - \\
\hline Test 2 & 4 & - \\
\hline Test 3 & 8 & - \\
\hline Test 4 & - & 4 \\
\hline Test 5 & - & 8 \\
\hline
\end{tabular}

The GPS coordinate of the two locations are Chanchaga co-ordinate - Latitude $9^{\circ} 36^{\prime} 50^{\prime \prime} \mathrm{N}$ longitude $6^{\circ} 33^{\prime} 25^{\prime \prime} \mathrm{E}$, Tunga coordinate - Latitude $9^{\circ} 16^{\prime} 60^{\prime \prime} \mathrm{N}$ Longitude 6³4'60" E.

\subsection{Green and Dry Strength Test}

Green compression strength test were performed on the prepared test sample. AFS specification was used to prepare the standard test specimen with sufficient measured quantity of tempered sand from the mixture prepared. The mixture placed in the specimen pedestal and rammed three times for tolerance. The specimen were removed from the container and fixed into compressive testing machine. Thereafter, for the dry compressive strength, the specimens were dried at $105^{\circ} \mathrm{C}$ for about 2 hours.

\subsection{Permeability Test}

Permeability or porosity of the moulding sand is the measure of its ability to permit air to flow through it. The moulding sand specimen is placed in a specimen tube, $2000 \mathrm{~cm}^{3}$ of air at a pressure of $980 \mathrm{~Pa}$ to pass through the specimen was noted to determine permeability of each sand samples, Permeability $\mathrm{P}$ is given as:

$\mathrm{P}=\frac{V X H}{P X A X t}$

Where $\mathrm{V}=$ Volume of air $\left(\mathrm{cm}^{3}\right)$

$$
\begin{aligned}
& \mathrm{H}=\text { height of the sand specimen }(\mathrm{cm}) \\
& \mathrm{P}=\text { Air pressure }(\mathrm{Pa}) \\
& \mathrm{A}=\text { Cross-sectional Area of sand specimen }=\frac{\pi}{4} \times H=\frac{\pi}{4} \times(50)^{2}=20.26 \mathrm{~cm}^{2} \\
& \mathrm{t}=\text { Time for air to pass through in minutes }
\end{aligned}
$$

\subsection{Green Shear Strength}

With sand similar to the test in green compression, a different adapter is fitted in the universal machine so that loading now be made for the shearing of the sand sample. The stress required to shear the specimen along the axis is then represent as the green shear strength. The green shear strength may vary from $10 \mathrm{kPa}$ to $50 \mathrm{kPa}$ (1.45Psi to $7.25 \mathrm{Psi}$ ).

\subsection{Moisture Content}

The moisture content test; moisture contents of the test specimens were determined using a moisture teller method. The instantaneous moisture content values in percentage were recorded from the instrument range.

Table 2: Chemical compositional analysis of Chanchaga and Tunga core making sand

\begin{tabular}{|l|c|c|}
\hline & \multicolumn{2}{|c|}{ Weight Percent Composition } \\
\hline Elements & Chanchaga & Tunga \\
\hline $\mathrm{SiO}_{2}$ & 92.70 & 88.77 \\
\hline $\mathrm{Al}_{2} \mathrm{O}_{3}$ & 2.50 & 4.24 \\
\hline $\mathrm{CaO}$ & 0.35 & 1.32 \\
\hline $\mathrm{MgO}$ & 1.41 & 0.98 \\
\hline $\mathrm{NaO}_{2}$ & 0.87 & 0.37 \\
\hline $\mathrm{Fe}_{2} \mathrm{O}_{3}$ & 0.98 & 1.63 \\
\hline $\mathrm{TiO}_{2}$ & 0.31 & 1.61 \\
\hline $\mathrm{K}_{2} \mathrm{O}$ & 0.41 & 0.47 \\
\hline
\end{tabular}




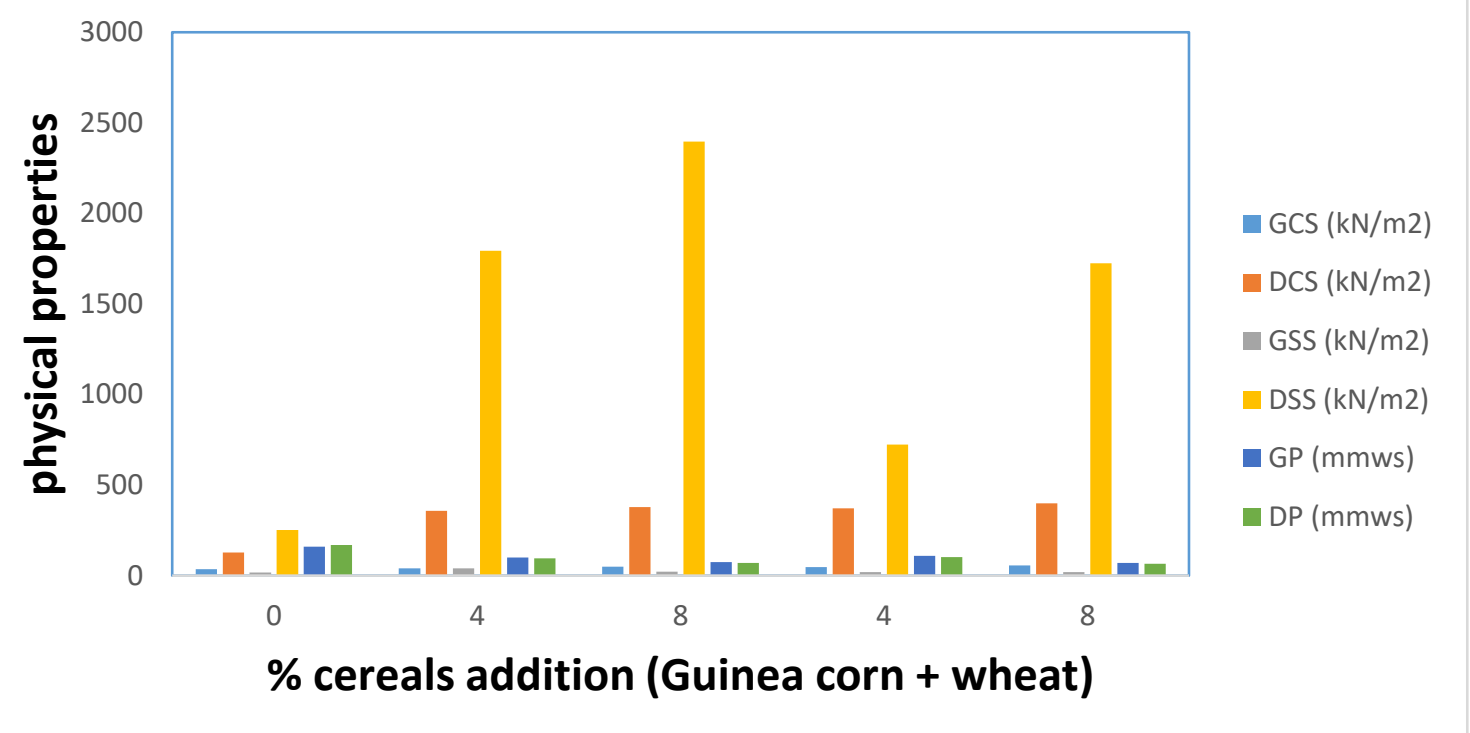

Fig 1: Effect of Guinea and wheat on the physical properties of Tunga Core-Making Sand at constant Moisture Content of 3\%

Note: the cereal (guinea corn + wheat) was varied, test: 0 , test $2: 4+0 \%$, test $3: 8+0 \%$, test $4: 0+4 \%$, test $5: 0+8 \%$.

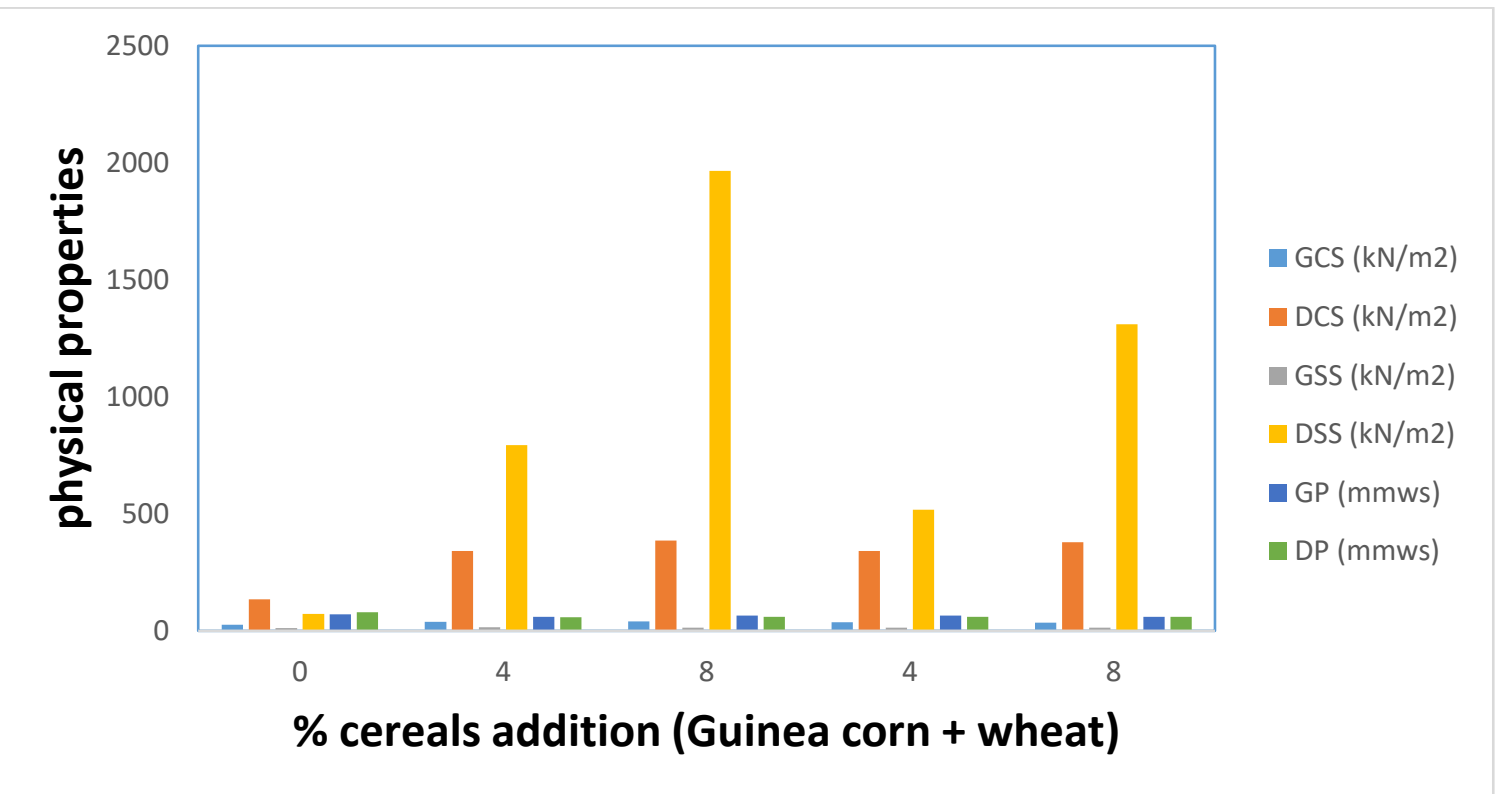

Fig 2: Effect of Guinea and wheat on the physical properties of Chanchaga Core-Making sand at constant Moisture Content of 3\%

Note: the cereal (guinea corn + wheat) was varied, test: 0 , test $2: 4+0 \%$, test $3: 8+0 \%$, test $4: 0+4 \%$, test $5: 0+8 \%$

\subsection{DISCUSSION OF RESULTS}

\subsection{Chemical Constituents}

The results of chemical composition of the two location (Chanchaga and Tunga) core-making sand are presented in Table 2. The results shows silicon dioxide $\left(\mathrm{SiO}_{2}\right)$ and Alumina $\left(\mathrm{Al}_{2} \mathrm{O}_{3}\right)$ as the major constituent with values ranging from $92.70 \%$ and $88.77 \%, 2.50 \%$ and $4.24 \%$ for the two deposits respectively. Silica are very important in moulding as they impact properties like refractoriness, chemical resistivity and permeability to the sand [8], the higher the percentage of silica sand, the better is the refractoriness of the sand. Other constituent present are oxide of calcium, magnesium, sodium, iron, titanium and potassium. This is in line with recommendation in literature [9]. However, from the chemical analysis of the core making sand determined, it can be opined that the two deposits are safe for use in sand casting foundry application.

\subsection{Moisture Content}

The moisture content of the core making sand was constant in this study. The aim is to bring to fore the effect of cereal with the purpose of significantly enhancing the properties of the sand as reported by [6]. It should be noted that moisture content is 
extremely critical parameter that needs to be considered. However, excess moisture content results in lowering of bond particles of the sand, weakening of the bond strength and poor bonding properties [10]. This setback can be overcome using moisture based additives while also improving on bonding and other properties.

\subsection{Green and Dry Compressive Strength}

The green compressive strength (GCS) and dry compressive strength (DCS) for Tunga and Chanchaga core making sand determined are represented in Fig. 1 and 2 respectively. Green strength is the strength of sand in wet state and is required for making it possible to prepare and handle the mould. If the metal is poured into a green mould, the sand adjacent to the metal dries and in the dry state it should have enough strength to resist erosion and the pressure of metal. Test sample $3-5$ gives GCS values of $49.64 \mathrm{KN} / \mathrm{m}^{2}, 48.26 \mathrm{KN} / \mathrm{m}^{2}$ and $55.85 \mathrm{KN} / \mathrm{m}^{2}$ for Tunga deposit while Chanchaga gives GCS value below $40 \mathrm{KN} / \mathrm{m}^{2}$ for all test samples. DCS values for both deposits falls within the standard ranges recommended for sand casting of different alloys except for test sample 1 which had a limited application as can be read from the representation in the figures. The strength of the sand that has been dried or baked is called dry strength. At the time of pouring the molten metal the mould most be able to withstand flow and pressure of the metal at high temperature otherwise the mould may enlarge, crack, get washed or break [11-12]. Green shear strength (GSS) and dry shear strength (DSS) gives maximum value at $15.86 \mathrm{KN} / \mathrm{m}^{2}, 1965.01$ $\mathrm{KN} / \mathrm{m}^{2}$ and $40 \mathrm{KN} / \mathrm{m}^{2}, 2395.93 \mathrm{KN} / \mathrm{m}^{2}$ for Tunga and Chachaga respectively. These values indicates that the additives are adequate to be used as binder in sand core making for ferrous and non-ferrous castings [13].

\subsection{Permeability}

Permeability number of a moulding sand depends on degree of fineness of the sand, as well as its moisture content [9]. Insufficient porosity (i.e. permeability) of moulding sand leads to casting defects such as holes and pores. The experimental results of the given permeability (GP) and dry permeability (DP) for the test samples prepared from the two deposits as presented in the bar graph (Figs. 1 and 2) indicate that the sand samples had good permeability values are within the standard range for most ferrous and non-ferrous metals $[5,12,15,16]$.

\subsection{CONCLUSION}

Comparative study on the effect of cereals (Guinea corn \& Wheat) on the physico-mechanical properties of two different core making sands deposits has been investigated and in conclusion the following were drawn:

1) The experimental analysis shows that the physico-mechanical properties of the two deposits as core making sand agree with the standard recommended properties for various types of casting.

2) The chemical analysis results for the silica sand indicates its suitability for moulding sand application.

3) That the mixture had a good permeability for casting ferrous and non-ferrous metals. Also the additives can best be substitute for imported ores.

\section{REFERENCES}

[1] Atanda and Ibitoye, "An Appraisal of Foundry Industries in Nigeria, A Way Forward", Proceeding of the 3rd Nigerian Materials Congress (NIMACON) and Meeting of the Nigerian Materials Research Society (Nigerian-MRS), 2004, Pp.22-29.

[2] A. Paul, J. Jecob J, M. Hamisu, The use of LP simplex method in the determination of the minimised cost of a newly developed core, J. Envirin. Sci., $2007,155-162$

[3] A. Ola, Development of oil sand cores, Ph.D Seminar paper; Department of Metallurgical and Materials Engineering, Ahmadu Bello University, Zaria, 1978, 6-12.

[4] O.S.I. Fayomi, Development of foundry core by using local raw material, Metallurgical and Foundry Department, Federal Polytechnic Idah, Nigeria 2006, 1-20.

[5] J.H. Debussy, Cast metal and core making technology, Journal of Material Science Technology, 1980, $23-29$.

[6] O.S.I. Fayomi, O.I. Ojo, and A.P.I. Popoola, Investigating (Ochadamu) silica sand, clay and local oils for foundry core, International Journal of the physical sciences, 6(8), 2011, 1894-1904.

[7] www.nona.net

[8] A.P. Ihom, and A. Offiong, Modelling of the Effect of Moulding Variable Parameters on some Properties of Clay- Bonded Sand. International Journal of Scientific and Engineering Research, 5(12), 2014, 1561-1571.

[9] F. Ademulegun, Manufacturing Processes (Tess-Tech Educational Publisher. Ikeja, Nigeria, 2008) 151-159.

[10] F.O. Edoziuno, C.C. Nwaeju, and O.G. UTU, Variation of moisture content with the properties of synthetic moulding content with the properties of synthetic moulding sand produced from River Niger sand (Onitsha Deposit) and Ukpor clay, International Journal of Research in Advanced Engineering and Technical. ISSN: 2455-0876, 3(2), 2017, Pp. 102-106.

[11] Z.A. Mshelia, M.S. Abolarin, O.K. Abubakre, and N.A. Ademoh, characterization of natural moulding sands from selected deposits in MaiduguriNigeria for casting applications, 12, 2016, 110-121.

[12] N.A. Ademoh and A.T. Abdullahi, "Assessment of Foundry Properties of Steel Casting Sand Moulds Bonded with the Grade 4 Nigeria Acadia Species (Gum Arabic)", International Journal of Physical Sciences, 4(4), 2009, pp. 238-241.

[13] A. Oyetunji, S.O. Seidu and A.I. Opaaluwa, Study on the shear strength of foundry sand cores using clay and cassava as Binder, International Journal of Engineering, 3, ISSN 15484 - 2673, 2013, 155-160.

[14] H. W. Dielert, Foundry Core Practice. American Foundry Men's Society. (3rd Ed.), (Des Plaines, 1966).

[15] A. M. Mikhailov, Metal Casting, (Mir Publishers. Moscow, 1989) Pp 71-82.

[16] Y.L. Shuaibu-Babata, Analysis of Ilorin sand moulding properties for foundry Applications, International Journal of Engineering Research and Technology (IJERT), ISSN: 2278-081, 3, 1520-1526. 